\title{
PERFIL DA DISPENSAÇÃO DE ANTIBIÓTICOS EM DROGARIAS NA CIDADE DE URUANA-GO
}

\author{
PROFILE OF ANTIBIOTIC DISPENSATION IN DRUGS IN CITY \\ URUANA-GO
}

\author{
Marcela Xavier da Silva Cruz \\ Discente do curso de Farmácia, Faculdade de Ceres-GO \\ marcelacruz.farm@hotmail.com

\section{Nayara Gontijo dos Santos} \\ Discente do curso de Farmácia, Faculdade de Ceres-GO \\ nayaragontijo@live.com
}

\section{Adriane Ferreira de Brito \\ Mestre em Ciências Farmacêuticas, docente da Faculdade de Ceres-GO \\ profadrianebrito@gmail.com}

RESUMO - INTRODUÇÃO: Antibióticos foram uma grande evolução para a saúde, entretanto o uso indiscriminado traz grandes problemas como a resistência bacteriana. Em fato desta intercorrência, a Agência Nacional de Vigilância Sanitária (ANVISA) estabeleceu a Resolução da Diretoria Colegiada (RDC) n 20/2011, tornando obrigatório a retenção da receita e a escrituração eletrônica no Sistema Nacional de Gerenciamento de Produtos Controlados (SNGPC), buscando minimizar a automedicação por antibióticos, onde o farmacêutico tem um importante papel, orientando o paciente quanto aos riscos da utilização destes medicamentos. OBJETIVOS: Avaliar a dispensação das classes de antibióticos em drogarias da cidade de Uruana-GO, verificando as principais patologias que acometem os usuários de antibióticos. METODOLOGIA: Trata-se de uma pesquisa de campo observacional de caráter quantitativo de corte transversal, sendo realizada a coleta de dados em drogarias da cidade de Uruana-GO, que se dispuseram a participar da pesquisa preenchendo os dados da planilha, entre os meses de fevereiro a Junho de 2015. RESULTADOS E DISCUSSÃA: O antibiótico mais dispensado no período da pesquisa foi a Amoxicilina com 22,10\% (156). A patologia mais relatada foi a infecção de garganta com 32,19\% (75). Esse medicamento por ser o mais antigo no mercado e possuir um amplo espectro de ação são um dos fatos que possibilitou estar na primeira colocaçao. CONCLUSÃO: No período de estudo foi observado o consumo total de 706 especialidades de antibióticos sendo o mais consumido a Amoxicilina, a classe dos betalactâmicos e a patologia mais relatada a infecção de garganta.

Palavras-chave: Atenção farmacêutica. Resistência bacteriana. Farmacoepidemiologia.

ABSTRACT - INTRODUCTION: Antibiotics were a major evolution for health, however indiscriminate use has many problems, such as, bacterial resistance. In fact this complication, the AgênciaNacional de VigilânciaSanitária (ANVISA) established the Resolução da DiretoriaColegiada (RDC) No 20/2011, mandating the retention of prescription and electronic bookkeeping in the SistemaNacional de Gerenciamento de ProdutosControlados (SNGPC) in order to minimize self-medication with antibiotics, 
where the pharmacist plays an important role in guiding the patient about the risks of using these drugs. AIMS: Evaluate the dispensation of antibiotic classes in drugstores in the city of Uruana-GO, and check the main pathologies that affect this antibiotic's users. METHODOLOGY: The research field observational, quantitative character and crosssectional. Data collection was realized in drugstores in city of Uruana-GO, who agreed participated of search, filling out worksheet data, between months of February to June 2015. RESULTS AND DISCUSSION: Antibiotics most dispensed, during study period, was amoxicilin with $22.10 \%$ (156). And, the condition most commonly reported was throat infection, $32.19 \%$ (75). CONCLUSION: In the study period, was observed the consumed of 706 types of antibiotics, being Amoxicillin the medicine most related, class of betalactam the class principal mentioned, and the throat infection disease most related the consume of antibiotics.

Keywords: Pharmaceutical attention. Bacterial resistance.Pharmacoepidemiology.

Endereço para correspondência:

Av. Brasil, S/N, Qd. 13, Morada Verde; Ceres-GO

CEP: 76300-000

Fone/Fax: (62) 3323-1040

e-mail: profadrianebrito@ hotmail.com

\section{INTRODUÇÃO}

Antibióticos são compostos naturais, semi-sintéticos e sintéticos, bacteriostáticos ou bactericidas, que começaram a ser pesquisados no início do século XIX, devido os microrganismos serem causadores de processos infecciosos. O inicio, do grande marco no tratamento das infecções bacterianas ocorreu em 1928 por Alexander Fleming, com a descoberta da penicilina (primeiro antibiótico biossintético), usada como bactericida (GUIMARÃES; MOMESSO; PUPO, 2010).

Essa evolução na utilização de antibióticos ocorreu mundialmente, possibilitando a existência de vários antibióticos disponíveis no mercado, tais como, a amoxicilina, azitromicina, ciprofloxacino, tetraciclina, entre outros. Estes sendo divididos por classes, sendo elasos betalactâmicos, macrolídeos, quinolonas e tetraciclinas, respectivamente (LIMAet al., 2008).

Os antibióticos foram uma grande revolução na medicina, sendo um forte aliado contra os microrganismos patógenicos aos homens. Contudo, o uso indiscriminado destes medicamentos, pela falta de conhecimento da posologia, efeito adverso, duração do tratamento, e interação medicamentosa, podem possibilitam uma maior probabilidade a resistência bacteriana (OLIVEIRA; MUNARETTO, 2010). 
Sobre a ocorrência de resistência bacteriana, Kobayashi et al. (2009) realizaram uma análise retrospectiva de dados relacionados a testes de suscetibilidade antibacteriana de isolados de Staphylococcus aureus e Pseudomonasaeruginosa de pacientes hospitalizados em um hospital público de Goiânia-GO. Nessa pesquisa foram isoladas 1960 bactérias, destas foram analisadas 1.239 cepas de $S$. aureus e 721 de $P$. aeruginosa. A resistência antibacteriana para $S$. aureus pode ser observada em maior proporção parapenicilina $(97,6 \%)$, eritromicina $(70,4 \%)$, clindamicina $(68 \%)$, oxacilina $(68,5 \%)$, gentamicina $(62,9 \%)$, sulfametoxazol-trimetoprim $(53,5 \%)$ e à ciprofloxacina $(53,1 \%)$. Já a resistência antimicrobiana para $P$. aeruginosa pode ser percebida para piperacilinatazobactam $(84,6 \%)$ e levofloxacina $(72,3 \%)$, carbapenen + imipenem $(69,1 \%)$ e meropenem (67,8\%). Desta forma acentua-se a importância da verificação de evidências clínicas no que diz respeito ao valor da identificação e determinação da suscetibilidade do microrganismo antes de se prescrever uma terapia antibacteriana.

Em decorrência douso indiscriminado dos antibióticos, a resistência bacteriana é uma das maiores preocupações das autoridades de saúde pública. Sendo assim, a Agência Nacional de Vigilância Sanitária (ANVISA) publicou a Resolução da Diretoria Colegiada (RDC) $\mathrm{n}^{\circ}$ 44/2010, que estabeleceu mecanismos para a prescrição e o controle da dispensação, substituindo-a pela RDC n²0/2011, que dispõe sobre antibióticos e acrescenta os serviços prestados pelo farmacêutico na dispensação desses produtos nas farmácias e drogarias particulares e públicas. Porém, a partir da RDC n 20/2011 consta a obrigatoriedade da escrituração no Sistema Nacional de Gerenciamento de Produtos Controlados (SNGPC) de medicamentos listados no ANEXO I, da legislação supracitada. A última atualização da Lista de antibióticos realizada pela ANVISA foi pela RDC $\mathrm{n}^{\mathrm{o}}$ 68/2014, que entrou em vigor no dia 16 de dezembro de 2014, totalizando 128 substâncias (BRASIL, 2010; 2011; 2014).

O uso indiscriminado de medicamentos pode ser minimizado em decorrência da atividade prestada pelo farmacêutico, pois ele é o responsávelpela interação usuáriomedicamento. Para tanto, a atenção farmacêutica visa realizar a anamnese do paciente, otimizando a antibioticoterapia, prevenindo, identificando e resolvendo problemas relacionados ao uso de medicamentos e orientando o paciente durante o ato da dispensação. Visando colaborar para o uso racional dos antibióticos, identificando a 
necessidade, efetividade e segurança das terapias medicamentosas prescritas (OBRELI NETO; VIEIRA; CUMAN, 2011).

Ressaltando que o farmacêutico tem um papel de extrema importância, a atenção farmacêutica contempla o monitoramento de parâmetros fisiológicos e bioquímicos de pessoas que utilizam medicamentos (BRASIL, 2009). Em 2010, um elevado número de mortes por infecção pela superbactéria KPC assustou os hospitais do país. Foram registradas 18 mortes no Distrito Federal, uma no Paraná e outras 22 pessoas infectadas em mais quatro estados. Recentemente a Secretaria de Saúde de Brasília confirmou a morte de três pacientes internadas no Hospital Regional de Taguatinga, contaminadas pelas superbactérias KPC e Enterococo. Baseado nesta situação ressalta-se a importância do papel do farmacêutico em minimizar o uso indiscriminado de antibióticos assim como reduzir a prática da automedicação, visando uma menor resistência bacteriana na população.

Este trabalho tem como finalidade analisar dispensação de antibióticos quanto a fórmula e forma farmacêutica, dispensação com ou sem receituário e quais as patologias que foram mais relatadas pelos pacientes, e bem como esclarecer através de palestras de conscientização ao publico que com a má utilização dos antibióticos podemos criar uma resistência dos microrganismos levando a morte do usuário.

\section{METODOLOGIA}

Foi realizada uma pesquisa de campo observacional de caráter quantitativo de corte transversal em três drogarias na cidade de Uruana-GO, durante os meses de Fevereiro à Junho de 2015.

Inicialmente sete drogarias de Uruana-GO foram convidadas a participarem da pesquisa, a partir da assinatura do termo de consentimento pelo proprietário do estabelecimento, contudo apenas três drogarias se propuseram a participarem e as demais drogarias foram excluídas da pesquisa.

Foram deixadas nas drogarias durante cinco meses consecutivos, planilhas contendo as variáveis: medicamento, forma farmacêutica, possível indicação e prescrição com ou sem receita. Esse levantamento foi realizado de Fevereiro a Junho de 2015, 
mediante a autorização do proprietário, sendo o farmacêutico responsável pela coleta dos dados.

O controle de qualidade destes dados ocorreu na observação da escrita nas planilhas onde observamos que se tratava da mesma caligrafia.

Utilizou-se essa metodologia para garantir que durante os meses pesquisados o máximo de medicamentos antibióticos vendidos fosse levantado na pesquisa.

Sendo a tabulação dos dados em frequiência relativa e construção de tabelas realizadas no software Microsoft Excel 2007® e a confecção de gráficos por meio do software GraphPadPrism versão 5.0.

\section{RESULTADOS E DISCUSSÃO}

A pesquisa foi realizada durante os meses de Fevereiro à Junho de 2015, em três drogarias da cidade de Uruana-GO. Nesse período foi observado um consumo total de 706 especialidades farmacêuticas antibacterianas, sendo os medicamentos mais consumidos a Amoxicilina com 22,10\% (156), seguido da Azitromicina com 12,32\% (87) e do Ciprofloxacino com 11,61\% (82) (Tabela 1).

Esses medicamentos descritos na Tabela 1 vendidos com receituário médico, a Amoxicilina em sua forma farmacêutica cápsula ou suspensão, respectivamente utilizada por adultos, crianças e/ou idosos. Esse alto consumo de Amoxicilina pode ser devido ao baixo preço e por ser um medicamento utilizado desde 1972, sendo considerado portanto tradicional. Dos clientes que fizeram o uso deste medicamento, a infecção de garganta foi uma das principais queixas, devido a mudanças climáticas e variações da temperatura acabar propiciando um aumento nas infecções respiratória do trato superior.

Tabela 1: Frequência de antibióticos mais dispensados no período de Fevereiro a Junho de 2015, em drogarias no município de Uruana-GO.

\begin{tabular}{lcc}
\hline Medicamento & $\begin{array}{c}\text { Frequência } \\
\text { Relativa (\%) }\end{array}$ & $\begin{array}{c}\text { Frequência } \\
\text { Absoluta (n) }\end{array}$ \\
\hline Amoxicilina & 22,10 & 156 \\
Azitromicina & 12,32 & 87 \\
Ciprofloxacino & 11,61 & 82 \\
Levofloxacino & 8,64 & 61 \\
\hline
\end{tabular}




\begin{tabular}{lll}
\hline Amoxicilina+ Clavulanato de potássio & 5,38 & 38 \\
Cefalexina & 4,82 & 34 \\
Sulfametoxazol+Trimetoprima (SMX+TMP) & 3,97 & 28 \\
Tetraciclina & 3,54 & 25 \\
Dexametasona+ Neomicina & 2,69 & 19 \\
Rifamicina & 2,27 & 16 \\
\hline
\end{tabular}

O estudo de Oliveira (2004), apresenta a Amoxicilina como o antibiótico mais requisitado, provavelmente pelo seu largo espectro de ação bactericida, evidenciando ser frequentemente utilizado em infecções de âmbito respiratório.

A amoxicilina é uma penicilina semi-sintética, possuindo amplo espectro de ação e característica ácido-resistente, mas que sofre inativação das betalactamases produzidas por várias bactérias (AZEVEDO, 2014). Esse medicamento, pertencente ao grupo dos Betalactâmicos, interfere na síntese da peptideoglicana da parede celular bacteriana, após se ligar as proteínas ligadoras da penicilina, ele inibe a enzima de transpeptidação, favorecendo a inativação de um inibidor das enzimas autolíticas na parede celular, ocorrendo o rompimento e causando a morte da bactéria. Em casos de resistência recomenda a utilização de um inibidor de betalactamases. Em decorrência da possível resistência a Amoxicilina pode-se observar na Tabela 1, em quinto lugar o consumo de Amoxicilina+Clavulanato de Potássio, essa associação foi desenvolvida devido ao Clavulanato de Potássio atuar irreversivelmente inibindo as enzimas betalactamases diminuindo a resistência de algumas bactérias.

O segundo antibiótico mais consumido, no período de estudo foi a Azitromicina com 12,32\% (87) (Tabela 1), medicamento muito utilizado devido a sua fácil posologia, sendo necessária apenas uma dose diária. A forma farmacêutica mais dispensada foi, comprimido. Entre os clientes que fizeram o uso da azitromicina, a principal queixa era infecção de garganta.

O consumo de azitromicina pode ser justificado considerando que esta tem sido recomendada como alternativa para o tratamento de faringite/tonsilite em pacientes alérgicos a penicilina, nas exacerbações agudas de bronquite, nas pneumonias de gravidade moderada em pacientes ambulatoriais. Além disso, sua dispensação acentuada está relacionada à sua indicação para alguns microrganismos que acometem o trato respiratório (WEBER et al., 2010). 
A Azitromicina pertence ao grupo dos macrolídeos e sua estrutura química contém um anel de lactona de 15 membros, sempre fixados a um ou mais desoaçúcares, ainda possui um átomo de nitrogênio metil-substituído no anel de lactona. Essas modificações moleculares permitem uma melhor estabilidade em ácido e a penetração tecidual, além de ampliar o espectro de atividade (MIRANDA, 2013).

Outro medicamento utilizado foi o Ciprofloxacino (Tabela 1), aparecendo em terceiro lugar com $11,61 \%$ (82), sendo dispensado, principalmente, para o tratamento de infecção do trato urinário, devido a melhor distribuição para esse tecido.

Devido ao aumento da resistência ao sulfametoxazol-trimetoprima (SMX-TMP) e aos betalactâmicos, as fluoroquinolonas - principalmente ciprofloxacino - tornaram-se os agentes de escolha em grande número de pacientes com infecções não complicadas e são alternativas de tratamento empírico. Em um regime de três dias o ciprofloxacino se mostrou equivalente ao SMX-TMP. Entretanto, tem sido demonstrado um aumento no número de relatos de Escherichia coli resistente a quinolonas, e este fato está relacionado ao seu consumo elevado, sendo que a Sociedade Americana de Doenças Infecciosas não recomenda seu uso como primeira linha de tratamento (MAZILI; CARVALHO JUNIOR; ALMEIDA. 2011).

Este fármaco inibe a atividade da DNA girase, também conhecida por topoisomerase II, enzima essencial à sobrevivência bacteriana, tornando a molécula de DNA compacta e biologicamente ativa. Ao inibir essa enzima, a molécula de DNA passa a ocupar grande espaço no interior da bactéria e suas extremidades livres determinam síntese descontrolada de RNA mensageiro e de proteínas, induzindo a morte das bactérias(MINARINI, 2008).

Além da quantificação dos princípios ativos mais consumidos, relacionando com as principais queixas este trabalho também se propôs a análise das classes farmacológicas de antibióticos mais consumidos. Dessa forma, na Figura 1(A) é possível observar a frequência de consumo de cada classe de antibiótico, sendo as três primeiras: os Betalactâmicos com 33,00\% (233), seguido das Associações com 24,36\% (172) e das Quinolonas com 20,96\% (148).

A classe dos betalactâmicos foi encontrada em primeiro lugar com 33,00\% (233) devido ser um dos antibióticos mais antigos, conhecido desde 1928, de amplo espectro seguro e com baixo custo para tratamento de diversas patologias. Dessa forma, a principal 
utilização desta classe foi descrito para o tratamento de infecções de garganta com $32,19 \%$ (75)(Figura 1B).

A maioria das sinusites, otites médias agudas e tonsilites têm etiologia viral e curso autolimitado, mas o uso de antibióticos para tratar essas infecções é muito comum, principalmente em três situações: paciente com queixa de dor de garganta; criança que apresenta hiperemia de membrana timpânica ou tosse com secreção e raio Xde seios da face com velamento (SIB; BRICKS, 2008).

Figura 1: (A) Classes antibacterianas mais consumidas e (B) principais patologias relatadas pelos consumidores como razão na utilização dos antibióticos das classes do Betalactâmicos, das Associações farmacêuticas contendo antibióticos e das Quinolonas, no município de Uruana-GO no período Fevereiro a Junho de 2015.

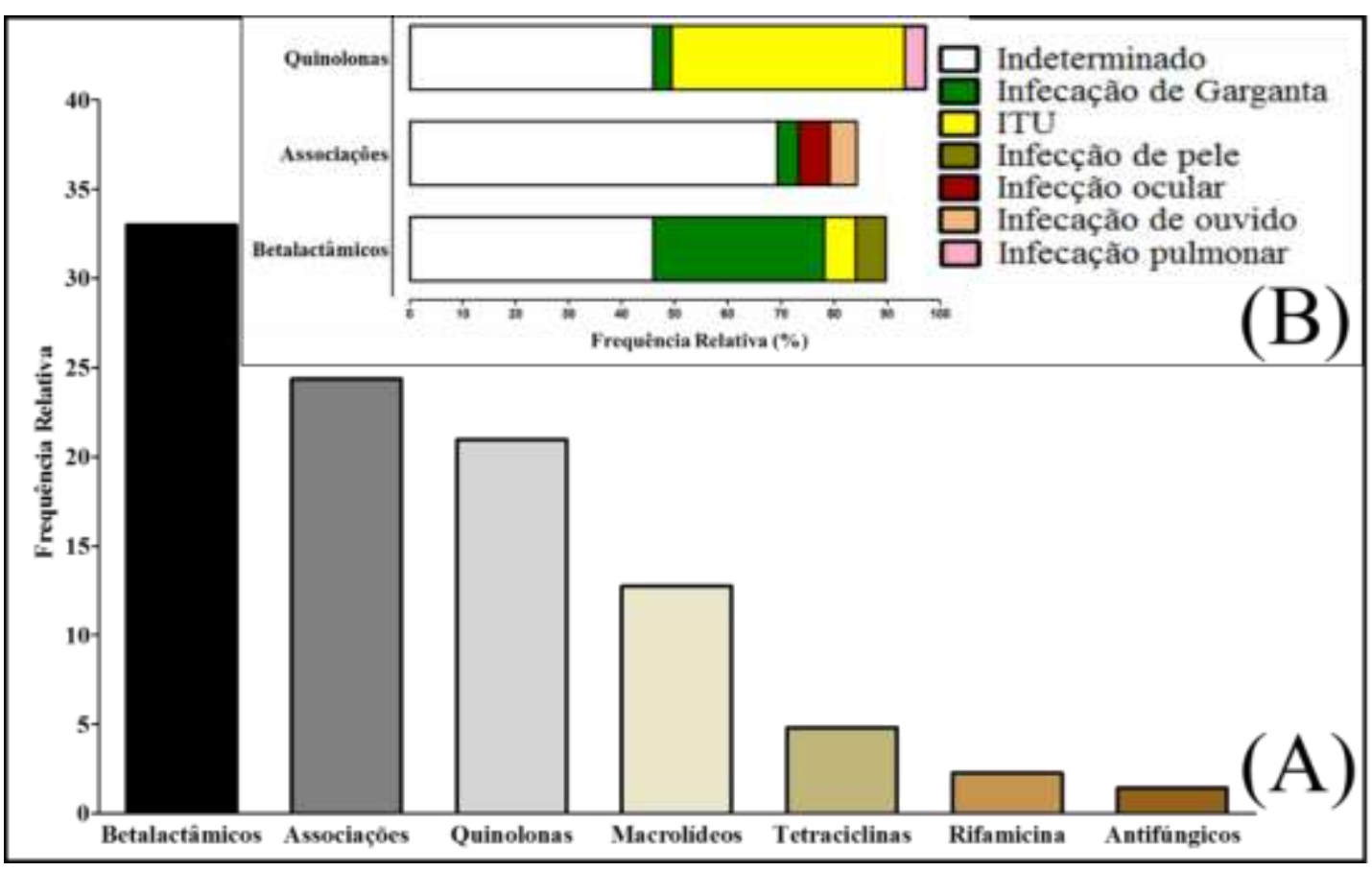

Os antibióticos betalactâmicos persistem como primeira opção para tratar as amigdalites bacterianas, tendo em vista a baixa prevalência de $S$. pyogenes resistentes a esses medicamentos e seu baixo custo comercial (SIB; BRICKS, 2008). Os betalactâmicos são considerados bastante seguros para o homem devido ao seu mecanismo de ação, que é específico para as células bacterianas, pois apenas estas possuem uma parede celular com peptideoglicano. Considera-se, portanto, que os betalactâmicos possuem baixa toxicidade direta. A lista de infecções onde se podem 
utilizar os betalactâmicos é extensa: otites do ouvido médio e externo, infecções articulares, cardíacas, biliares, amigdalites, faringites, infecções brônquicas, pulmonares, entre muitas outras, causadas por inúmeras bactérias. Esta família de antibióticos além do seu largo espectro de ação possui características farmacocinéticas que os tornam muitos úteis, tal como uma boa distribuição nos fluídos e tecidos corporais, alguns terem a capacidade de penetrar a barreira hemato-encefálica e serem na sua maioria excretados por via urinária, entre outras (AZEVEDO, 2014).

Entretanto, a amoxicilina (uma penicilina de amplo espectro) foi a droga individualmente mais utilizada, em detrimento das penicilinas benzatina ou oral, de custo bem mais acessível. As penicilinas foram também os medicamentos mais referidos na pesquisa de Calva et al. (1996), na qual representaram $43 \%$ dos antibacterianos consumidos. Nos domicílios brasileiros pesquisados por Marliére et al. (2000), a amoxicilina foi a droga mais frequentemente referida pelos entrevistados. No estudo de Thrane et al.(1999), as penicilinas representaram 88\% das prescrições de antibacterianos no ano em estudo. Nesse mesmo trabalho, os autores demonstraram preocupação pela alta indicação de penicilinas de amplo espectro (amoxicilina e ampicilina), quando as taxas de resistência aos antibióticos são reconhecidamente baixas no Brasil (BERQUÓ et al., 2004).

A segunda classe mais consumidaforam as Associações com 24,36\% (172) (Figura 1A), essas especialidades farmacêuticas são medicamentos compostos por dois ou mais princípios ativos, com o objetivo de melhorar a terapêutica minimizando a resistência do microrganismo, tendo como a infecção ocular uma das principais patologiastratadas por essas formulações com5,81\% (10) (Figura 1B).

Visando diminuir a resistência bacteriana dos Betalactâmicos, é recomendada a utilização de um inibidor de betalactamases. Para tanto é adicionado outro composto químico, que inibe a atividade dessa enzima. São então utilizados o ácido clavulânico, o sulbactam e o tazobactam. Não são totalmente epecificos contra todos os tipos de betalactamases, mas ampliam o espetro de ação quando bem associados (AZEVEDO, 2014).

As quinolonas são a terceira classe de antibióticos mais consumidos com 20,96\% (148)(Figura 1A), utilizada principalmente para o tratamento de infecção do trato urináriocom47,97\% (71) (Figura 1B), isso acontece pelo falto da alta distribuição do 
tecido renal alcançando melhor as vias urinárias além de o seu valor comercial ser mais em conta.

Devido às elevadas concentrações que atingem no trato urinário, as quinolonas constituem a principal classe de drogas utilizadas no tratamento destas infecções. $O$ norfloxacino tem boa ação nas cistites, ao passo que o uso do ciprofloxacino tem boa ação nas pielonefrites. São drogas que funcionam por concentração, ou seja, mantém um efeito pós-antibiótico, que é a capacidade que a droga tem de manter ação ainda que bacteriostática em concentrações inferiores à sua concentração inibitória mínima (LOPES et al., 2012).

De acordo com Santos (2012), as principais indicações clínicas das Quinolonas seriam para: uso em trato genito-urinário, trato gastrintestinal, trato respiratório, osteolielites, partes moles e ação contra microbactérias. As Quinolonas foram desenvolvidas a partir de modificações na estrutura do ácido nalidíxico, um dos membros mais antigos, utilizado na prática clínica por muitos anos para o tratamento de infecções do trato urinário.Desse modo, são fármacos que podem ser utilizados no tratamento de muitas doenças infecciosas em nível ambulatorial ou hospitalar, apresentando, no entanto, grande potencial para abuso (BESEN, 2008).

Considerando que a atenção farmacêutica seria de extrema importância, o farmacêutico pode minimizar ou até mesmo impossibilitar a dispensação inadequada ou a falta de informação quanto ao uso de antibióticos, retardando e inibindo a resistência bacteriana (BRASIL, 2009). Essa multirresistência tem aumentado em decorrência da prática da automedicação que junto com o uso indiscriminado de antibióticos favorece a resistência bacteriana (FIOCRUZ, 2010).

Apesar de todos os dados levantados, esta pesquisa possui algumas limitações, o fato das planilhas serem preenchidas por funcionários da drogaria pode comprometer alguns dados, pois algumas informações podem ter sido preenchidas de forma irreal. Como por exemplo, a questão da presença ou a falta da prescrição médica onde se dispensa o medicamento sem receita. Outro ponto que poderia ter ocorrido seria a venda de alguns antibacterianos e por esquecimento não ter anotado na planilha com isso não teríamos o real número de medicamentos dispensados, interferindo em nossa pesquisa. Contudo, os dados obtidos permite discutir o principal foco do trabalho que é o uso indiscriminado de antibacterianos e o papel do farmacêutico nesse consumo. 


\section{CONCLUSÃO}

Verificou-se através do presente estudo que o medicamento mais consumido foi a Amoxicilina. Em relação à classe terapêutica mais utilizada foram os betalactâmicos, possivelmente em decorrência de infecções do trato respiratório superior. A segunda classe mais consumida foram as Associações, tendo como infecção ocular uma das principais patologias tratadas.As quinolonas são a terceira classe de antibióticos mais consumidos, sendo utilizado para o tratamento de infecção do trato urinário.

Além disso, nesse trabalho ressaltou-se que o farmacêutico tem um importante papel no uso indiscriminado, podendo minimizar o uso indiscriminado de antibióticos assim como reduzir a prática da automedicação, visando uma menor resistência bacteriana na população.

\section{AGRADECIMENTOS}

As autoras agradecem aos proprietários e funcionários das drogarias que participaram desta pesquisa.

\section{REFERÊNCIAS}

AZEVEDO, S.M.M. Farmacologia dos Antibióticos Betalactâmicos. Mestrado Integrado em Ciências Farmacêuticas. Faculdade de Ciências da Saúde - Universidade Fernando Pessoa, Porto, 2014.

BERQUÓ, L.S. et al. Utilização de antimicrobianos em uma população urbana. Rev. Saú. Púb.,v. 38, n. 2, p. 239-46, Pelotas/RS, 2004.

BESEN, Z.G.S. Análise do padrão de consumo dos antimicrobianos no Hospital Universitário da Universidade Federal de Santa Catarina no período de 2000 a 2006. Programa de Pós-Graduação em Farmácia - Florianópolis, 2008. 
BRASIL, ANVISA, Resolução da Diretoria Colegiada (RDC) no 20, 05 de maio de 2011. Dispõe sobre o controle de medicamentos à base de substâncias classificadas como antimicrobianos, de uso sob prescrição, isoladas ou em associação. Diário Oficial da União, n 87, 9 de mai de 2011. Seção 1, p. 39-41.

BRASIL, ANVISA, Resolução da Diretoria Colegiada (RDC) $\mathrm{n}^{\circ}$ 44, 17 de agosto de 2009. Dispõe sobre Boas Práticas Farmacêuticas para o controle sanitário do funcionamento, da dispensação e da comercialização de produtos e da prestação de serviços farmacêuticos em farmácias e drogarias e dá outras providências. Diário Oficial da União.

BRASIL, ANVISA, Resolução da Diretoria Colegiada (RDC) nº 44, 26 de out de 2010. Dispõe sobre o controle de medicamentos à base de substâncias classificadas como antimicrobianos, de uso sob prescrição médica, isoladas ou em associação e dá outras providências. Diário Oficial da União.

BRASIL, ANVISA, Resolução da Diretoria Colegiada (RDC) $n^{\circ}$ 68, 28 de novembro de 2014. Dispõe sobre a atualização do Anexo I, Lista de Antimicrobianos Registrados na Anvisa, da Resolução - RDC no 20 , de 5 de maio de 2011 e dá outras providências. Diário Oficial da União, n 232, 1 de dez de 2014. Secção 1, p. 37-38.

CALVA, J.; BOJALIL, R. Antibiotic use in a periurban community in Mexico: a household and drugstore survey. Soc. Sci. Med., v. 42, p.1121-8, ed. 8, 1996.

FIO CRUZ - Fundação Oswaldo Cruz - Ministério da Saúde. Estudo sobre bactérias multirresistentes a antibióticos recebe prêmio em simpósio, 20 de out de 2010. Disponível em: <http://www.agencia.fiocruz.br/estudo-sobre-bact\%C3\%A9riasmultirresistentes-a-antibi\%C3\%B3ticos-recebe-pr\%C3\%AAmio-emsimp\%C3\%B3sio>, Acesso em: 20 de out de 2015.

GUIMARAES, D.O.; MOMESSO, L.S.; PUPO, M.T. Antibióticos: importância terapêutica e perspectivas para a descoberta e desenvolvimento de novos agentes. Quím. Nova, São Paulo, v. 33, n. 3, p. 667-679, 2010.

KOBAYASHI, C.C.B.; SADOYAMA, G.; VIEIRA, J.D.G. Determination of associated antimicrobial resistance in clinical isolates of Staphylococcus aureusand Pseudomonas aeruginosain a public hospital in Goiânia, State of Goiás. Rev. Soc. Bras. Med. Trop., v. 42, n. 4, p. 404-410, 2009. 
LIMA, A.P.C.S. et al. Utilização de um sistema de gerenciamento de benefícios farmacêuticos (PBM) para a caracterização do perfil de prescrição e aquisição de antibióticos. Rev. Bras. Cienc. Farm., São Paulo, v. 44, n. 2, p. 215-223, Jun. 2008.

LOPES, P.M. et al. Escherichia coli como agente etiológico de infecções do trato urinário em pacientes do município de Viçosa-MG. Rev. Bras. Farm. v. 93, n. 1, p. 43 47, 2012.

MARLIÈRE, G.; FERRAZ, M.; QUIRINO DOS SANTOS, J. Consumo ambulatorial e sobras de antibióticos: entrevista em 6000 domicílios brasileiros. Rev. Bras. Med., v. 57, p. $187-95,2000$.

MAZILI, P.M.L.; CARVALHO JUNIOR, A.P.; ALMEIDA, F.G. Infecção do trato urinário. Grupo Editorial Moreira Jr., v. 68, n. 12, Dez. 2011.

MINARINI, L.A.R. Estudo dos mecanismos de resistências às quinolonas em enterobactérias isoladas de alguns estados brasileiros. Tese (Doutorado - Biociências Aplicadas à Farmácia). Faculdade de Ciências Farmacêuticas de Ribeirão Preto Universidade de São Paulo, Ribeirão Preto, 2008.

MIRANDA, A.C. Desenvolvimento de um método para monitoramento da contaminação do solo pelo fármaco Azitromicina: Uma abordagem sustentável. Programa de mestrado em Engenharia de Produção. Universidade Nove de Julho - UNINOVE, São Paulo, 2013.

OBRELI NETO, P.R.; VIEIRA, J.C.; CUMAN, R.K.N. Impacto da atenção farmacêutica no uso racional de antimicrobianos em uma unidade básica de saúde no interior do Estado de São Paulo. Acta Scien.:Healt. Scie., Maringá, v. 33, n. 2, p. 159-164, 2011.

OLIVEIRA, A.O.T.et al. Atenção farmacêutica na antibioticoterapia. Visão Acadêmica, Curitiba, v. 5, n. 1, p. 7-14, Jan/Jun, 2004. Disponível em:<http://ojs.c3sl.ufpr.br/ojs2/index.php/academica/article/viewFile/536/449>, Acesso em: 20 de out de 2015.

OLIVEIRA, K.R.; MUNARETTO, P. Uso racional de antibióticos: Responsabilidade de Prescritores, Usuários e Dispensadores. Rev. Cont. \&Saú.,Ijuí, editora Unijuí, v. 9, n. 18, p. 43-51, Jan/Jun, 2010. 
SANTOS, V.G. A importância da orientação farmacêutica as pacientes que fazem o uso concomitante de anticoncepcional e antibiótico da classe das quinolonas. Rev.Ceciliana, v. 4, n. 1, p. 86-89, Jun/2012.

SIB, T.M.; BRICKS, L.F. Otimizando o diagnóstico para o tratamento adequado das principais infecções agudas em otorrinopediatria: tonsilite, sinusite e otite média. Rev. Bras. DeOtorrinolaringol, v.74, n. 5, p. 755-62, Set/Out, 2008.

THRANE, N. et al. A population-based study of antibiotic prescriptions for Danish children.Pediatr. Infect. Dis. Jou., v. 18, p. 333-7, 1999.

WEBER, B.R. et al. Análise da variação sazonal da prescrição de antibióticos aos usuários de uma unidade básica de saúde do município de Ijuí/RS. Rev. Cont. \&Saú., Ijuí, editora Unijuí, v. 10, n. 19, p. 117-121, Jul/Dez, 2010. 